\title{
Prevalence of nonvitamin, nonmineral supplement usage among students in a Turkish university Unal Ayranci*1, Nazan Son ${ }^{2}$ and Osman Son ${ }^{3}$
}

\author{
Address: ${ }^{1}$ Medico Social Center, Osmangazi University 26480 Meselik Eskisehir Turkey, ${ }^{2}$ Medical Faculty, Dietitian Division, Osmangazi \\ University 26480 Meselik Eskisehir Turkey and ${ }^{3}$ Medical Faculty, Internal illnesses Department, Osmangazi University 26480 Meselik Eskisehir \\ Turkey \\ Email: Unal Ayranci* - unalayranci@yahoo.com; Nazan Son - nazanson@mynet.com; Osman Son - nazanson@mynet.com \\ * Corresponding author
}

Published: 16 May 2005

BMC Public Health 2005, 5:47 doi:10.1 I86/147|-2458-5-47
Received: 03 December 2004

Accepted: 16 May 2005

This article is available from: http://www.biomedcentral.com/I47/-2458/5/47

(C) 2005 Ayranci et al; licensee BioMed Central Ltd.

This is an Open Access article distributed under the terms of the Creative Commons Attribution License (http://creativecommons.org/licenses/by/2.0), which permits unrestricted use, distribution, and reproduction in any medium, provided the original work is properly cited.

\begin{abstract}
Background: There have been multiple studies carried out in many countries with regard to the use of nonvitamin, nonmineral (NVNM) supplements. These studies have shown that the use of NVNM supplements is on the increase throughout the world, particularly in western countries. The aim of this study was to assess the extent of NVNM supplement use among Turkish university students.
\end{abstract}

Methods: The survey was conducted between September and December 2004 at Osmangazi University, a public university located in the west of Turkey. Responses were analysed, using the chi-square $\left(\mathrm{x}^{2}\right)$ test, $t$ test and percent $(\%)$ ratios, according to gender and consumers. Differences were considered significant for $\mathrm{p} \leq 0.05$.

Results: Of 2253 students attending the university, 187I participated in the survey (909 men and 962 women). Overall, the prevalence of NVNM supplement use was $16.5 \%$ (16.6\% in men and $16.3 \%$ in women, $p<0.05$ ).

The three most commonly given reasons for use were 'improvement of energy and vitality (78.6\%)', 'promotion of weight loss (71.l\%)', followed by 'enhancement of athletic performance (64.3\%)'. Twenty-six of the 308 reported NVNM users $(26 / 308,8.4 \%)$ reported having experienced an adverse reaction. Television (76.3\%), magazines/newspapers (4I.5\%) and internet websites (37.3\%) were the most frequently used sources for obtaining information about NVNM supplements. The three most frequently used NVNM supplements were echinacea, ginseng, and gingko biloba (38.6\%, $36.4 \%$, and $32.8 \%$, respectively). Nutritional scores were higher in NVNM supplement users than in non-users $(66.510 .8$ vs. 62.712 .7$)(p<0.00 I)$. Users and nonusers of NVNM supplements differed significantly according to sex, age, Body Mass Index (BMI) values, types of school, mother and fathers' education levels, family income, most permanent place of residence up to the time of survey, smoking status, and participating in sports.

Conclusion: The results indicate that the prevalence of NVNM supplement use is relatively modest among Turkish university students and more information is needed on why people use particular NVNM supplements. 


\section{Background}

Dietary supplements are defined in the United States Dietary Supplement Health and Education Act of 1994 (United States DSHEA) as any product (other than tobacco) intended to supplement the diet that bears or contains one or more of the following ingredients: a vitamin, a mineral, an herb or other botanical, an amino acid, a supplement used by man to supplement the diet by increasing the total dietary intake, or a concentrate, metabolite, constituent, extract, or combination of any ingredient described above [1].

Hankin [2] and Radimer et al. [3] used the term 'nonvitamin, nonmineral (NVNM) supplements' to differentiate a new class of dietary supplements. NVNM supplements include products such as chrondroitin, sulfate, kava kava, ginseng, echinacea, ginkgo biloba, garlic herbals, botanicals, protein and amino acids, as well as Brewer's yeast and shark cartilage [3-5].

Although use of NVNM supplements is increasing in popularity, patterns of use for these supplements are not well known, and what is available is not always consistent, clear, or easily accessible [3].

People have reported a variety of reasons for taking dietary supplements, including decreasing their susceptibility to health problems such as stress, colds, heart attacks, osteoporosis, neural tube defects, dental caries and cancer, as well as to increase energy [6,7]. The supplements typically can be considered as falling into three distinct categories: supplements that are believed to add nutrients to a system that owing to inadequate dietary practices might otherwise be lacking [8]; supplements that allege rapid weight loss and maintenance of the loss [9], or conversely, supplements that are believed to result in weight gain or muscle development [10]. Furthermore, the rise in popularity of freely available substances purported to enhance performance, such as androsterone (a steroid precursor), and creatine (an amino acid derivative), has also been documented $[11,12]$. To date, however, the taking of nutritional preparations has not consistently indicated a competitive advantage other than a possible placebo effect, or one resulting from the treatment of concurrent nutritional deficiencies [13]. Consequently, according to the United States Commission on Dietary Supplement Labels, it is important for health and nutrition professionals to become more knowledgeable about all types of dietary supplements in order to help consumers make appropriate choices [14].

Variables that have been found to have a relationship with supplement use are race or ethnicity, age, education, income and lifestyle variables such as drinking, smoking, and exercising $[15,16]$.
There is documented evidence that the use of NVNM supplements in western society is high, and its use is increasing worldwide [17-20].

In some countries, such as Germany, many botanical products are classified as drugs, and thus are subject to quality, safety, and efficacy regulations [21]. In the United States, although it is acknowledged that some dietary supplements, particularly botanicals, are used to prevent and treat diseases, DSHEA distinguishes these products from drugs and food additives and thus they are not subject to the same regulations $[1,4,5]$. Use of NVNM supplements increased substantially with the passage of the DSHEA [1], which gave manufacturers greater freedom to market more products as dietary supplements and to provide information about their purported benefits in package labeling and advertising. Although the United States Food and Drug Administration (FDA) regulates additives and drugs, premarket review of dietary supplements is minimal [22].

The use of NVNM supplements has increased recently in many countries, a fact also reflected in our country. However, while the worldwide rate of consumption of these supplements is near to $50 \%$ [17-19], it is still rather low in developing countries. This may be put down to indications that those with higher education and income levels seem to be comparatively more likely to use supplements [15]. In Turkey, there is no regulation of NVNM supplements in that they are widely available over the counter from such places as pharmacies and markets without a prescription. There is no regulation or health policy on the use of NVNM supplements, and furthermore, data on the prevalence and use of NVNM supplements are limited or non-existent [23]. Finally, there is a need to understand the frequency with which people use supplements and what variables are associated with particular frequencies of use.

In general, although we consider Turkish NVNM supplement consumption to fit into the prevalence patterns for developing countries, to our knowledge, no data is available either concerning use in Turkish students or the population as a whole. For this reason, the objective of this survey was to quantify the prevalence of NVNMS usage among university students; to identify supplements consumed and rationale for usage; to identify sources of supplement information; and to relate usage to selected demographic characteristics.

\section{Methods \\ Sampling}

The survey was conducted between September 2004 and December 2004 at Osmangazi University, a public university located in the west of Turkey. All students from the 
schools of medicine, engineering and architecture, science and literature, economics, education, and the college of health services were invited to participate. Participation was voluntary and anonymous, and the Director of the Institution approved the survey.

\section{Subjects}

Subjects were randomly selected with a stratified sampling method. Osmangazi University is an urban, mid-sized university with six schools, all of which were included in the survey. At least one class from the first, second, third and fourth years in each department were randomly selected to participate in the survey. The sample size for the survey was determined by multiplying at least $10 \%$ by the number of the students: the total numbers of the students in each department and in our survey, respectively, were 1097 and 203 for the school of medicine; 4212 and 561 for the school of engineering and architecture; 3556 and 403 for the school of science and literature; 1394 and 178 for the school of economics; 858 and 177 for the school of education; and 302 and 212 for the college of health services.

Students were excluded from the survey due to: unwillingness to participate $(\mathrm{n}=186)$, handing in incomplete questionnaires $(\mathrm{n}=87)$, and non-attendance of class $(\mathrm{n}=$ 109). Thus, the response rate for sample respondents was $83 \%(1871 / 2253)$ of 2253 subjects, with ages ranging from 17 to 28 , leaving a total of 1871 students (962 women, 909 men).

\section{Questionnaire and interview schedules}

Completion of the questionnaire was self-reporting on the part of the students. The dates on which the study would be conducted were determined in cooperation with class teachers in the schools concerned. The students completed questionnaires in the presence of a member of the research team.

\section{The first section of questionnaire}

This section identified consumption of NVNM supplements during the survey or the past year, previous use of dietary supplements, and the probability of students considering the use of NVNM supplements in the near future. If participants reported having used a NVNM supplements during the survey period or the year prior to the study, they were further questioned on a number of topics related to consumption: the number used; the name of the product(s), 73 of which were written on the questionnaire; frequency of use of each product; total product consumption; length of product use; the reasons for using NVNM supplements, revised from previous studies [24,25]; and general demographic information such as age, sex, cigarette smoking, body height and weight, affiliation to which school of the university, class, marital sta- tus, parents' education level, and parents' total income level.

\section{The second section of questionnaire}

This section included the items related to nutritional beliefs about NVNM supplements. Subjects' views about NVNM supplement use and the health benefits associated with it were used to assess the motivational factors related to supplement use in this population. Items were based on those of previous studies [24-28], and also contained the most frequently consumed food items in the Turkish population. Twenty two opinions were expressed, consisting of such items as 'vitamins and minerals can provide energy', 'maintain health', increase longevity', 'reduce stress' 'prevent colds', 'improve mental function', 'reduce the risk of chronic diseases', or 'aid in recovery from fatigue', all of which were assessed to be commonly-held assumptions connected with use of the supplements. For this section, a five-point Likert scale was used, and responses were scored from one (disagree very strongly) to five (agree very strongly). Thus, the higher score showed a stronger belief on the students' part that NVNM supplements could provide specific health benefits. Applying it to a sample of 59 randomly selected students from same schools assessed the reproductivity of the questionnaire. The students who participated in the test/retest procedure were not included in the final analyses.

\section{Statistical analysis}

Frequency, mean, and standard deviation (SD) were calculated, and the $t$ test compared scores on nutritional beliefs between users and non-users, or women and men. The chi-square test $\left(\mathrm{x}^{2}\right)$ examined the relation between general characteristics and NVNM supplements use. The percentages of the reasons cited for using NVNM supplements arranged according to sex, were calculated by first extracting out of the total figure male and female students' numbers for NVNM supplements usage, and the significance between men and women was evaluated using cross tables. The reliability of the internal consistency of data concerning nutritional beliefs collected from the pretest was calculated by Cronbach's alpha and was found to be 0.96 , indicating a high internal consistency across nutritional-belief statements. Consequently, belief statement use was used for the final survey. Statistical analyses were performed using SPSS for Windows (Version 10.0, SPSS Inc., Chicago, Illinois). The standard used for statistical significance was $\mathrm{p} \leq 0.05$. The data were analyzed using descriptive statistics including means, standard deviations, and frequency distributions.

\section{Results}

Of the participants, 909 (48.6\%) were men and 962 $(51.4 \%)$ women. The average age of the participants was 19.9 years (range $=17$ to 28 years). Nearly half of the 
Table I: General characteristics of users and non-users of nonvitamin/nonmineral supplements

\begin{tabular}{|c|c|c|c|}
\hline & $\begin{array}{c}\text { Non-users } \\
n(\%) \\
\text { 1563(83.5) }\end{array}$ & $\begin{array}{c}\text { Users } \\
n(\%) \\
308(16.5)\end{array}$ & $\begin{array}{c}\text { Total } \\
n(\%) \\
\text { I } 87 \mid(100.0)\end{array}$ \\
\hline Sex & & $x^{2}=5.594 ; p=0.018$ & \\
\hline Men & $758(83.4)$ & $151(16.6)$ & $909(48.6)$ \\
\hline Women & $805(83.7)$ & $157(16.3)$ & $962(51.4)$ \\
\hline Ages & & $x^{2}=35.732 ; p=0.000$ & \\
\hline$\leq 18$ & $358(86.7)$ & $55(13.3)$ & $413(22.1)$ \\
\hline $19-20$ & $789(84.6)$ & $144(15.4)$ & $933(49.9)$ \\
\hline $21-22$ & $292(85.1)$ & $51(14.9)$ & $343(18.3)$ \\
\hline$\geq 23$ & $124(68.1)$ & $58(31.9)$ & $182(9.7)$ \\
\hline BMI values & & $x^{2}=73.392 ; p=0.000$ & \\
\hline Underweight $(<18.5)$ & 199(67.7) & $95(32.3)$ & $294(15.7)$ \\
\hline $\begin{array}{l}\text { Normal weight ( } \geq 18.5-\leq \\
\text { 24.99) }\end{array}$ & $1212(86.6)$ & $187(13.4)$ & $1399(74.8)$ \\
\hline Overweight $(\geq 25-\leq 29.9)$ & $121(90.3)$ & $13(9.7)$ & $134(7.2)$ \\
\hline Obese $(\geq 30-\leq 39.9)$ & $31(70.5)$ & $13(29.5)$ & $44(2.4)$ \\
\hline Type of school & & $x^{2}=23.573 ; p=0.000$ & \\
\hline Medicine & I64(79.2) & $43(20.8)$ & $207(11.1)$ \\
\hline Engineering and architecture & $536(88.4)$ & $70(11.6)$ & $606(32.4)$ \\
\hline Science and literature & $332(82.4)$ & $7 I(17.6)$ & $403(21.5)$ \\
\hline Economics & 204(79.7) & $52(16.9)$ & $256(13.7)$ \\
\hline Education & $144(77.0)$ & $43(23.0)$ & $187(10.0)$ \\
\hline College of health services. & $183(86.3)$ & $29(13.7)$ & $212(11.3)$ \\
\hline Year in school & & ns & \\
\hline Freshman & $570(85.6)$ & $96(14.4)$ & $666(35.6)$ \\
\hline Sophomore & $556(80.8)$ & $132(19.2)$ & $688(36.8)$ \\
\hline Junior & $168(86.2)$ & $27(13.8)$ & $195(10.4)$ \\
\hline Senior & $269(83.5)$ & $53(16.5)$ & $322(17.2)$ \\
\hline Marital status & & ns & \\
\hline Single & $1520(83.7)$ & $296(16.3)$ & $1816(97.1)$ \\
\hline Married & $33(82.5)$ & $7(17.5)$ & $40(2.1)$ \\
\hline Divorced/widow(er)/separated & $10(66.7)$ & $5(33.3)$ & $15(0.8)$ \\
\hline Mother's education level & & $x^{2}=11.940 ; p=0.008$ & \\
\hline Primary school and lower & $848(84.8)$ & $152(15.2)$ & $1000(53.4)$ \\
\hline Secondary school & $106(74.1)$ & $37(25.9)$ & $143(7.6)$ \\
\hline High school & $395(84.9)$ & $70(15.1)$ & $465(24.9)$ \\
\hline College or university & $2 \mid 4(81.4)$ & $49(18.6)$ & $263(14.1)$ \\
\hline Father's education level & & $x^{2}=7.807 ; p=0.050$ & \\
\hline Primary school and lower & $416(87.6)$ & $59(12.4)$ & $475(25.4)$ \\
\hline Secondary school & $149(83.2)$ & $30(16.8)$ & $179(9.6)$ \\
\hline High school & $537(81.7)$ & $120(18.3)$ & $657(35.1)$ \\
\hline College or university & $461(82.3)$ & $99(17.7)$ & $560(29.9)$ \\
\hline Family income & & $x^{2}=22.971 ; p=0.000$ & \\
\hline Low & $763(86.7)$ & $117(13.3)$ & $880(47.0)$ \\
\hline Moderate & $566(83.4)$ & $113(16.6)$ & $679(36.3)$ \\
\hline High & $234(75.0)$ & $78(25.3)$ & $312(16.7)$ \\
\hline $\begin{array}{l}\text { Most permanent place of } \\
\text { residence }\end{array}$ & & $x^{2}=13.642 ; p=0.001$ & \\
\hline Village/town & $|4|(79.7)$ & $36(20.3)$ & $177(9.5)$ \\
\hline City & $1207(85.3)$ & $208(14.7)$ & $1415(75.6)$ \\
\hline Metropolis & $215(77.1)$ & $64(22.9)$ & $279(14.9)$ \\
\hline Smoking status & & $x^{2}=15.435 ; p=0.000$ & \\
\hline Nonsmoker & $1093(85.7)$ & $183(14.3)$ & $1276(68.2)$ \\
\hline Current smoker & $390(80.1)$ & $97(19.9)$ & $487(26.0)$ \\
\hline Former smoker & $80(74.1)$ & $26(25.9)$ & $108(5.8)$ \\
\hline Participation in sport & & $x^{2}=9.193 ; p=0.010$ & \\
\hline No & $724(82.5)$ & $154(17.5)$ & $878(46.9)$ \\
\hline Former & $580(82.4)$ & $124(17.6)$ & $704(37.6)$ \\
\hline Yes & $259(89.6)$ & $30(10.4)$ & $289(15.4)$ \\
\hline
\end{tabular}


Table I: General characteristics of users and non-users of nonvitamin/nonmineral supplements (Continued)

\begin{tabular}{lccc}
\hline Exercise & $440(83.5)$ & $x^{2}=12.205 ; p=0.002$ & $527(28.2)$ \\
Never & $862(85.6)$ & $87(16.5)$ & $1007(53.8)$ \\
Fewer than 3 times per month & $261(77.4)$ & $145(14.4)$ & $337(18.0)$ \\
More than 3 times per month & $76(22.6)$ & ns & $481(25.7)$ \\
Self-reported health & $400(83.2)$ & $81(16.8)$ & $1390(74.3)$ \\
Fair/poor & $1163(83.7)$ & $227(16.3)$ & \\
Good-excellent & & & \\
\hline
\end{tabular}

Table 2: Reasons cited for using nonvitamin/nonmineral supplements by sex

\begin{tabular}{|c|c|c|c|c|}
\hline & $\begin{array}{c}\text { Men } \\
n(\%) \\
15 \mid(49.0)\end{array}$ & $\begin{array}{c}\text { Women } \\
n(\%) \\
\text { I } 57(51.0)\end{array}$ & $\begin{array}{c}\text { Total } \\
\mathrm{n}(\%) \\
308(100.0)\end{array}$ & $x^{2} ; P$ values \\
\hline Improve energy and vitality & $128(49.6)$ & II4(50.4) & $242(78.6)$ & ns \\
\hline Promote weight loss & $92(42.1)$ & $127(57.9)$ & $219(71.1)$ & $5.59 ; 0.018$ \\
\hline Enhance athletic performance & $117(59.1)$ & $81(40.9)$ & $198(64.3)$ & $6.54 ; 0.011$ \\
\hline Retard aging & $124(63.6)$ & $7 I(46.4)$ & $195(63.3)$ & $|4.4| ; 0.000$ \\
\hline Burn-up fat & $55(35.1)$ & $102(64.9)$ & $157(50.9)$ & 14.07; 0.000 \\
\hline Prevent(threat) colds(sore throat) & $4 I(35.4)$ & $75(64.6)$ & $116(37.6)$ & $9.97 ; 0.002$ \\
\hline Promote skin(hair) health & $4 I(4 I .8)$ & $57(58.2)$ & $98(31.8)$ & ns \\
\hline Build muscle & $7 I(74.3)$ & $24(25.7)$ & $95(30.8)$ & $23.25 ; 0.000$ \\
\hline Supplement inadequate diet due to nutrition deficiency & $48(53.9)$ & $4 I(46 . I)$ & $89(28.9)$ & ns \\
\hline Improve memory & $33(39.3)$ & $5 I(60.7)$ & $84(27.3)$ & $3.86 ; 0.05$ \\
\hline Relieve stress (improve mood) & $29(37.7)$ & $48(62.3)$ & $77(25.0)$ & $4.67 ; 0.03$ \\
\hline Improve sexual function & $55(79.7)$ & 14(20.3) & $69(22.4)$ & $24.36 ; 0.000$ \\
\hline Enhance sleep & $22(52.4)$ & $20(47.6)$ & $42(13.6)$ & ns \\
\hline Reduce dangers of cigarette smoking & $18(52.9)$ & $16(47.1)$ & $34(11.1)$ & ns \\
\hline Improve circulation & $18(58.1)$ & $13(41.9)$ & $31(10.1)$ & ns \\
\hline Gain weight & $18(62.1)$ & $\mathrm{II}(37.9)$ & $29(9.4)$ & ns \\
\hline Prevent illnesses such as cancer, osteoporosis, menopause, hypertension, kidney stones & $9(42.9)$ & $12(57.1)$ & $21(6.8)$ & ns \\
\hline
\end{tabular}

Note: Subjects could list more than one reason for nonvitamin, nonmineral supplement usage

students $(49.9 \%)$ were between the ages of $19-20$. Most (74.8\%) were of normal weight. More than $50 \%$ of the students $(53.9 \%)$ were from the schools of engineering and architecture, and science and literature. Most students $(72.4 \%)$ were in their freshman or sophomore years. Almost $100 \%$ (97.9\%) were single or divorced. The proportion of students whose mothers had an education level of secondary school and lower was $61.0 \%$, with the figure of $35.0 \%$ reported for students' fathers. Most students' level of family income $(47.0 \%)$ was low. The majority of the students reported living in villages or cities $(85.1 \%)$, and $26.0 \%$ were current smokers. The percentage of those participating in sport was $15.4 \%$, and $18.0 \%$ reported exercising more than 3 times per month. Most $(74.3 \%)$ rated their health as 'good/excellent'. There were significant differences between men and women according to all the descriptive information. The more detailed general characteristics of users and non-users of NVNM supplements are shown in Table 1.
The duration of supplement use was cited as 'between 1 and 6 months' by $65.3 \%$, followed by 'between 6 and 12 months' and 'more than one year' $(23.1 \%$ and $11.7 \%$, respectively). More than $50 \%$ of supplement users $(53.6 \%)$ were taking just one supplement at the time of this survey, followed by those using 2 supplements $(38.6 \%)$ and 3 or more $(7.8 \%)$. The average number of supplement taken was 1.6 (standard deviation $=0.6$ ). Most students (68.2\%) rated the frequency of supplement use as 'once/twice a day' (37.0\%) or 'once every other day' (31.2\%), followed by 'once/twice a week' (20.5\%) and 'once/twice a month' (11.4\%). No difference was revealed between men and women by supplement use (Unshown data).

Table 2 presents reasons cited for using NVNM supplements. The four most commonly given reasons for use were 'improvement of energy and vitality' (78.6\%), 'promotion of weight loss' $(71.1 \%)$, followed by 'enhance- 
Table 3: Prevalence of use of nonvitamin, nonmineral supplements

\begin{tabular}{ll}
\hline & Total \\
& $\mathbf{n}(\%)$ \\
& $\mathbf{3 0 8}(100.0)$ \\
\hline Echinacea & $119(38.6)$ \\
Ginseng & $112(36.4)$ \\
Gingko biloba & $101(32.8)$ \\
Protein powder and or Amino acids & $89(28.9)$ \\
Fish oil & $84(27.3)$ \\
Bee pollen & $78(25.3)$ \\
Garlic & $64(20.8)$ \\
Green Tea & $61(19.8)$ \\
Bee pollen & $57(18.5)$ \\
St. John's wort & $51(16.5)$ \\
Ginger & $47(15.2)$ \\
Creatine & $45(14.6)$ \\
Aloe & $27(8.7)$ \\
Lecithin & $25(8.1)$ \\
Flax & $21(6.8)$ \\
Chestnut seed & $19(6.2)$ \\
Valerian & $16(5.2)$ \\
Burdock root & $15(4.9)$ \\
Coenzyme Q & $15(4.9)$ \\
Goldenseal & $12(3.9)$ \\
Cranberry & $11(3.6)$ \\
Guarana & $9(2.9)$ \\
Chamomile tea & $8(2.6)$ \\
Sam-E & $7(2.3)$ \\
Kava kava & $7(2.3)$ \\
Melatonin & $6(1.9)$ \\
Dong Quai & $4(1.3)$ \\
Angelica & $3(0.9)$ \\
Cayenne & $2(0.6)$ \\
Borage & $2(0.6)$ \\
Astragalus & $1(0.3)$ \\
Evening primrose & $1(0.3)$ \\
\hline & \\
\hline & \\
& \\
& \\
&
\end{tabular}

The percentages total to more than $100 \%$ because some respondents reported taking more than one NVNM supplement

ment of athletic performance' (64.3\%) and 'retardation the onset of aging' (63.3\%). Women were more likely to be using supplements to promote weight loss, burn-up fat, prevent colds, improve memory, and relieve stress; whereas men were more likely to use supplements to enhance athletic performance, retard the onset of aging, build muscle, and improve sexual function.

In general, when the scores obtained from all the nutritional beliefs between men and women were taken into consideration, women agreed on the effects obtained from taking NVNM supplements more strongly than men in the categories: 'important in maintaining health', 'stress reduction', and 'enhancement sleep', whereas men agreed more strongly on 'improvement sexual function' than women (Unshown data).
Twenty-six of the 308 NVNM users (26/308, 8.4\%) reported having had an adverse reaction to an NVNM supplement. Of 26, the two most adverse effects were nausea and vomiting $(61.5 \%, 30.7 \%$, respectively), followed by gastrointestinal disturbances (15.4\%), flashing (11.5\%) and liver insufficiency $(7.7 \%)$, Subjects could list more than one complication cited for NVNM usage (Unshown data).

The most frequent used sources for obtaining information about supplements were television (76.3\%), magazines/ newspapers $(41.5 \%)$ and internet websites $(37.3 \%)$; followed by family $(20.1 \%)$, friends $(19.8 \%)$, school and teachers $(16.5 \%)$, books (13.3), radio $(5.8 \%)$, health food stores $(0.5 \%)$ and agricultural engineers $(0.3 \%)$. The rates of those citing dietetic professionals, and doctor and nurse as their sources were only $4.2 \%$ and $6.8 \%$, respectively (Unshown data).

Of 1871,308 students (16.5\%) reported using NVNM supplements during the past year, $23.0 \%$ students indicated that they were considering NVNM use in the near future. About $10 \%(9.7 \%)$ reported past usage. The data revealed no difference between men and women according to supplement usage. There were also no differences between men and women in the categories 'use of NVNM during the past year', 'considering NVNM supplement use in the future', and 'past usage of NVNM supplements' ( $p$ $>0.05$ for each one) (Unshown data).

Of the 1690 students reporting no use of NVNM supplements in the past, $44.3 \%$ indicated that they had not considered using supplements, $34.7 \%$ reported that they had only thought about using supplements, and 11.6\% reported that they had been unaware of the presence of supplements. There was a $9.4 \%$ non-response rate (Unshown data).

Table 3 summarizes information regarding the prevalence of NVNM supplement use. The three most commonly used supplements were reported as echinacea, ginseng, and gingko biloba $(38.6 \%, 36.4 \%$, and $32.8 \%$, respectively). Since all of the 73 most commonly purchased supplements in Turkey and the world were listed on the questionnaire, the students reported using no supplements other than those listed.

Table 4 shows that NVNM supplement use correlated to nutritional beliefs. Of all the beliefs, the links between 'supplement use and recovery from fatigue' and 'supplement use and prevention/threat colds/sore throat' were the ones with which users and non-users most agreed. The lower degree of perception of any 'relationship between supplement use and improved mental health' was similar between users and non-users. In general, when all the 
Table 4: Nutritional beliefs about nonvitamin/nonmineral supplements of supplement users and non-users*

\begin{tabular}{|c|c|c|c|}
\hline Belief statement & $\begin{array}{c}\text { Non-userst } \\
n(\%) \\
\text { I563(83.5) }\end{array}$ & $\begin{array}{c}\text { Users } \dagger \\
\text { n(\%) } \\
\text { 308( } 16.5)\end{array}$ & $P$ values $\ddagger$ \\
\hline Improve energy and vitality & $2.8 \pm 0.8$ & $3.2 \pm 0.8$ & 0.000 \\
\hline Important in maintaining health & $2.9 \pm 0.8$ & $3.3 \pm 0.8$ & 0.000 \\
\hline Provide living longer & $2.7 \pm 0.8$ & $2.8 \pm 0.7$ & 0.000 \\
\hline Help recovery from fatigue & $3.0 \pm 0.8$ & $3.3 \pm 0.7$ & 0.000 \\
\hline Reduce stress & $2.8 \pm 0.7$ & $3.0 \pm 0.8$ & 0.012 \\
\hline Prevent/threat colds/sore throat & $3.1 \pm 0.8$ & $3.2 \pm 0.7$ & ns \\
\hline Prevent mental illnesses & $2.7 \pm 0.8$ & $2.8 \pm 0.8$ & ns \\
\hline Improve mental health & $2.6 \pm 0.8$ & $2.7 \pm 0.8$ & 0.016 \\
\hline Reduces risk of chronic illnesses & $2.8 \pm 0.7$ & $3.0 \pm 0.8$ & 0.000 \\
\hline Retard aging & $2.7 \pm 0.9$ & $2.9 \pm 0.8$ & 0.000 \\
\hline Burn fat accumulating in the body & $2.9 \pm 0.8$ & $2.8 \pm 0.8$ & ns \\
\hline Promote weight loss more & $2.8 \pm 0.7$ & $2.9 \pm 0.8$ & ns \\
\hline Build muscle more & $2.9 \pm 0.8$ & $3.1 \pm 0.7$ & 0.000 \\
\hline Enhance athletic performance & $2.9 \pm 0.8$ & $3.1 \pm 0.8$ & 0.001 \\
\hline Enhance sleep & $2.8 \pm 0.8$ & $3.0 \pm 0.8$ & 0.000 \\
\hline Improve sexual function & $2.8 \pm 0.8$ & $3.0 \pm 0.8$ & 0.000 \\
\hline Improve circulation & $2.9 \pm 0.8$ & $3.2 \pm 0.7$ & 0.000 \\
\hline Supplement inadequate diet due to nutrition deficiency & $2.9 \pm 0.8$ & $3.2 \pm 0.8$ & 0.000 \\
\hline Improve memory & $2.8 \pm 0.8$ & $3.0 \pm 0.8$ & 0.001 \\
\hline Promote skin/hair health & $2.9 \pm 0.8$ & $3.1 \pm 0.8$ & 0.000 \\
\hline Gain weight & $3.0 \pm 0.8$ & $3.1 \pm 0.8$ & 0.009 \\
\hline Reduce dangers of cigarette smoking & $2.7 \pm 0.9$ & $2.8 \pm 0.9$ & ns \\
\hline
\end{tabular}

*Values are shown as mean \pm standard deviation

† A five-point Likert scale was used; disagree very strongly (one point) to agree very strongly (five points)

$\ddagger t$ test

nutritional beliefs between users and non-users were taken into consideration, users agreed on the effects obtained from taking NVNM supplements more strongly than non-users except for the categories of 'prevention/ threat of colds/sore throat', 'prevention of mental illnesses', 'burning-up fat accumulating in the body', 'promotion of more weight loss', and 'reduction of the harmful effects of cigarette smoking'. Of the 22 beliefs, the score from only one item, 'burning-up fat accumulating in the body' was found to be lower in users than in the nonusers.

\section{Discussion}

To our knowledge, this is the first survey on NVNM supplements use conducted in Turkey. This survey allowed the assessment of the prevalence of NVNM supplement use in a sample of university students from different departments.

Our results indicate that about one in six students $(16.5 \%)$ consumed one or more NVNM supplement during the past year. While our finding is compatible with some other study results, it is not with others: Radimer $e t$ al. [3] found that between 3.3 and $12 \%$ of respondents to their survey reported using NVNM supplements in 1994 and 1995, respectively. In a survey on a 1000 non-patient student population by Perkin et al. [25], a NVNM supplement usage rate of $26.3 \%$ was observed. Eisenberg et al. [29] reported this proportion as $12.1 \%$. Furthermore, in a survey relevant to NVNM supplement use over a 12month period by adult members of a large health maintenance organization, an estimated $32.7 \%$ of adults used at least one NVNM supplement [30]. Newberry et al. [31] reported that out of 272 college students canvassed, $48.5 \%$ had taken an NVNM supplement during the previous year and in a survey in the United States, it was found that $14.5 \%$ of the adults reported having used a NVNM supplement during the previous year [32]. The aforementioned studies show that the rate of NVNM supplement usage ranges from 3.3 to $48.5 \%$. One explanation for these differences in reported usage rates could be the variation in how questions were asked regarding time frame and the types of supplements used. A further possibility could be relevant to individuals' sociodemographic characteristics, such as race or ethnicity, age, education, income and lifestyle variables such as drinking, smoking, and exercising $[15,16]$. 
As in other populations, echinacea, ginseng, gingko biloba, and protein powder and or amino acids were reported by this population to be the most popular supplements [3,33-35]. Wingate [33] found that in 1997 the three most reportedly used supplements were garlic, ginseng, and ginkgo biloba. Similarly, the three most commonly consumed NVNM supplements reported in the Slone Survey [36], conducted from 1998 to 1999, were ginseng, ginkgo biloba extract, and allium sativum. This high use of supplements in Turkey and the rest of the world may be due to the fact that those products are prevalent in the market.

In this survey, most students reported that they were healthy. This was reflected in the rationale offered by the students for supplement usage, such as increasing energy and enhancing athletic performance.

In this survey, a positive relationship was seen to exist between exercising and NVNM supplement usage. Both behaviors may be perceived as congruent with disease prevention. NHANES III [3] also found a positive relationship between exercise and NVNM usage.

The current survey found that former smokers used NVNM supplements most, which is in line with the NHANES III survey [3]. One explanation for this is that usage could be viewed as offsetting a negative behavior [25].

In this survey, $9.7 \%$ of the students reported past usage, $16.5 \%$ currently usage and $23.0 \%$ potential for use in the future. That these findings show increasing trends in the use of supplements with a corresponding increase in time may be due to media reports or advertisements in local newspapers about provision of energy and vitality, an increase in athletic performance, the retarding of aging, and the reduction of the risk of chronic diseases such as hypertension, colon cancer, breast cancer, kidney stones, and osteoporosis [37-39]. A further explanation may be that the use of NVNM supplements increased substantially with the passage of the United States Dietary Supplement Health and Education Act of 1994 (DSHEA), which gave manufacturers greater freedom to market more products through purported benefits reported in package labeling and adverting [1].

Twenty-six of the 308 NVNM users $(26 / 308,8.4 \%)$ reported having experienced an adverse reaction to an NVNM supplement. This rather high rate is in line with results published by Newberry et al. [31], which reported a reaction rate of $6.9 \%$. This may be due to the fact that the majority of the students did not seek nutrition information from reliable sources such as doctors, nurses or dietetic professionals. In this survey, only $11.0 \%$ of supplement users cited doctors, nurses, and dietetic professionals as sources of information. However, it is important that students get nutrition information from reliable sources and receive proper nutrition education. To put this another way, that $76 \%$ of the respondents obtained information about supplementation from television may indicate that television has enormous implications for educational and public policy initiatives, and that television should be used to get more health information about supplementation.

The nutritional beliefs that subjects questioned had concerning supplements were an important factor for their use of supplements. Supplement users agreed more strongly than non-users on the health benefits of supplement use for the majority of items. Others reported similar findings $[9,26]$.

In this survey, NVNM supplement use was higher in men than in women, in line with Radimer et al.' survey [3]. However, these findings are not concordant with data reported from Malaysia (40), where the prevalence of supplement use was higher in women $(14.9 \%$ vs. $9.7 \%$, respectively). No apparent reasons were disclosed for such differences; it is possible that NVNM supplement use might be related to a desire to increase athletic performance in men [41], but further studies are needed to better assess this result.

In this survey, nutritional knowledge average scores were low in both sexes $(63.3 \pm 12.4$ for a maximum score of $110)$, probably because of the absence of nutritional education in primary, secondary, high schools or university in our country.

NVNM supplement use by the students was different according to sex, age, Body Mass Index (BMI) values, school type, mother and fathers' education levels, family income, most permanent place of residence, smoking status, participating in sport, and exercise. This finding shows that the rationale for supplements use changes according to subjects' general characteristics.

Of further interest is the trend for more female students in the current sample to indicate use of significantly more supplements than males. Parallel to our survey, this finding highlights the fact that female students are more likely to be dieting to lose weight, whereas male students are more likely to be controlling their diet to gain weight and build muscle, which is compatible with some other studies $[42,43]$.

We are well aware of the limitations of the present survey. Firstly, it was performed in a single institution, and therefore the sample may not be representative of all Turkish 
students. Another limitation on the data was the use of the self-reporting system employed in this survey. This may have given rise to bias.

\section{Conclusion}

This descriptive analysis helps to provide a clearer picture of NVNM supplement use. Not only does it indicate that students are indeed using or considering using supplements as a viable means to achieve their short-term fitness and or appearance goals, but also which products are most likely to be used, and indeed which individuals are most in need of education and information concerning the use and abuse of certain dietary aids. Further research, therefore, needs to focus on how NVNM nutritional supplements use information can be applied to specific user groups.

Monitoring the use of NVNM supplements within the community or university students should be of interest because these substances may affect health or interact with other medications [44]. The respondents in this survey reported 85 cases of interactions between St John's wort and prescription medications. Dietetic professionals and physicians need to consider evaluating NVNM supplement use when assessing overall nutrient and medication use by clients or students.

In summary, our results in this sample of Turkish students indicate that the prevalence of NVNM supplement use is still relatively modest, and neither associated with a healthier lifestyle nor related to a better nutritional knowledge. The need for further research on the relationships between dietary supplements and health has also been highlighted in the 1997 report by the United States Commission on Dietary Supplement Labels [45].

\section{Competing interests}

The author(s) declare that they have no competing interests.

\section{Authors' contributions}

AU conceived of the study, performed its design and coordination, sequence alignment, collected the data, performed the statistical analyses and drafted the manuscript, SN and SO collected the data and entered the data to SPSS packet program, All authors read and approved the final manuscript.

\section{Acknowledgements}

We thank all the students from the University of Osmangazi, Eskisehir, who participated in this survey, and the lecturers of the schools, who helped in the collection of data.

\section{References}

I. Dietary Supplement Health and Education Act of 1994. Publ No. 103-4I 7, 108 Stat 4325 . October 25, 1994
2. Hankin J: Keeping up with the increasing popularity of nonvitamin, nonmineral supplements. J Am Diet Assoc 2000, 100:419-420.

3. Radimer KL, Subar AF, Thomsan FE: Nonvitamin, nonmineral dietary supplements: Issues and findings from NHANES III. J Am Diet Assoc 2000, 100:447-454.

4. Nesheim MC: Regulation of dietary supplements. Nutr Today 1998, 33:62-68.

5. Nesheim MC: What is the research base for the use of dietary supplements? Public Health Nutr 1999, 2:35-38.

6. Worthington RB, Breskin M: Supplementation patterns of Washington State dietitians. I Am Diet Assoc 1984, 84:795-800.

7. Read MH, Bock MA, Carpenter K, Medeiros D, Ortiz M, Raab C, Schutz $H$, Sheehan E, Williams DK: Health beliefs and supplement use: adults in seven western states. J Am Diet Assoc 1989, 89: $|8| 2-18 \mid 3$.

8. Schulz IO: Factors influencing the use of nutritional supplements by college students with varying levels of physical activity. Nutr Res 1988, 8:459-466.

9. Thompsen PA, Terry RD, Amos RJ: Adolescents' beliefs about and reasons for using vitamin/mineral supplements. J Am Diet Assoc 1987, 87: 1063-1065.

10. Wolfe RR: Protein supplements and exercise. J Am Clin Nutr 2000:55I-557.

II. Rubinstein ML, Federman DG: Sports supplements. Can dietary additives boost athletic performance and potential? Postgrad Med 2000, 108: 103-106.

12. Smith J, Dahm DL: Creatine use among a select population of high school athletes. Mayo Clin Proc 2000, 75: I257-I 263.

13. Clarkson PM: Nutrition for improved sports performance. Current issues on ergogenic aids. Sports Med 1996, 21:393-40I.

14. National Institutes of Health: What are Dietary Supplements? Office of Dietary Supplements Web Site [http://dietary-supple ments.info.nih.gov/whatare.html]. Accessed February 8, 2000

15. Messerer $M$, Johansson S-E, Wolk A: Sociodemographic and health behaviour factors among dietary intake among dietary supplement and natural remedy users. Eur J Clin Nutr 200I, 55:1104-1110.

16. Greger JL: Dietary supplement use: consumer characteristics and interests. J Nutr 200I, I 3 I:1339S-1343S.

17. Eisenberg DM, Kessler RC, Foster C, Norlock FE, Calkins DR, Delbanco TL: Unconventional medicine in the United StatesPrevalence, Costs, and Patterns of Use. N Engl J Med 1993, 328:246-252.

18. Fisher P, Ward A: Medicine in Europe: Complementary medicine in Europe. BMJ 1994, 309:107-III.

19. MacLennan AH, Wilson DH, Taylor AW: Prevalence and cost of alternative medicine in Australia. Lancet 1996, 347:569-573.

20. Barnes J, Abbot NC, Harkness EF, Ernst E: Articles on complementary medicine in the Mainstream medical literature: an investigation of MEDLINE, 1966 through 1996. Arch Intern Med 1999, 159:1721-5.

21. Mitka M: FDA never promised an herb garden-but sellers and buyers eager to see one grow. JAMA 1998, 280:1554-I556.

22. Kurtzweil P: An FDA guide to dietary supplements. FDA Consumer 1998, 32:28-35.

23. Erozturk N: Bir Yudum Saglik,. Anahtar Kitaplar yayinevi, Istanbul 2000.

24. Kim SH, Han JH, Keen $\mathrm{CL}$ : Vitamin and mineral supplement use by healthy teenagers in Korea: Motivating factors and dietary consequences. Nutrition 200I, 1 7:373-380.

25. Perkin JE, Wilson WJ, Schuster K, Rodriguez J, Chabot AL: Prevalence of nonvitamin, nonmineral supplement usage among university students. J Am Diet Assoc 2002, 102:4I2-4I4.

26. Eldridge AL, Sheehan ET: Foot supplement use and related beliefs: survey of community college students. J Nutr Edu I994, 26:259.

27. Sobal J, Muncie HL: Vitamin/mineral supplement use among adolescents. J Nutr Edu 1988, 20:3।4.

28. Bell A, Dorsch KD, Mccreary DR, Hovey R: A look at nutritional supplement use in adolescents. J Adolescent Health 2004, 34:508-516.

29. Eisenberg DM, Davis RB, Ettner SL, Appel S, Wilkey S, Rombay MV, Kessler RC: Trends in alternative medicine use in the United States, 1990-1997: Results of a follow-up national survey. JAMA 1998, 280:1569-1575. 
30. Americans' Food and Nutrition Attitudes and Behaviors: American Dietetic Association's Nutrition and You. Trends 2000 [http:// www.eatright.org/pr/2000/01030a.html]. Accessed October 2, 2004

31. Newberry H, Beerman K, Duncan S, McGuire M, Hillers V: Use of nonvitamin, nonmineral dietary supplements among college students. J Am Coll health 200I, 50:123-129.

32. Millen $A E$, Dodd KW, Subar AF: Use of vitamin, mineral, nonvitamin, nonmineral, and nonmineral supplements in the United States: The 1992, and 2000 National Health Interview Survey Results. J Am Diet Assoc 1987, 104:942-950.

33. Wingate P: Consumers not supplement brand survey. In Natural Food Merchandiser Boulder, CO: New Hope Communications; 1998.

34. Bennet J, Brown CM: Use of herbal remedies by patients in a health maintenance organization. J Am Pharm Assoc (Wash) 2000, 40:353-358.

35. Planta M, Gundersen B, Petitt JC: Prevalence of the use of herbal products in a low-income population. Fam Med 2000, 32:252-257.

36. Kaufman DW, Kelly JP, Rosenberg L, Anderson TE, Mitchell AA Recent patterns of medication use in the ambulatory adult population of the United States: The Slone Survey. JAMA 2002, 287:337-344.

37. Miller GD, Anderson Jj: The role of calcium in prevention of chronic diseases. J Am Coll Nutr 1999:37I-372.

38. Singh V, Raidoo D, Harries CS: The prevalence, patterns of usage and people's attitude towards complemantaryand alternative medicine among the Indian community in Chatsworth, South Africa. BMC Complementary and Alternative Medicine 2004, 3: I-7.

39. Fennel D: Determinants of supplement usage. Preventive Med 2004, 39:932-939.

40. Mazlan Bin Y: Vitamin use and beliefs among students at a Malaysian university. I R Soc Health 1990, I I 0: I32-134.

4I. Schwenk TL, Costley CD: When food becomes a drug: nonanabolic nutritional supplements use in athletes. Am J Sports Med 2002, 30:907-916

42. Rosen JC, Gross J: Prevalence of weight reducing and weight gaining in adolescent girls and boys. Health Psychol 1987, 6:131-147.

43. McCreary D, Sasse DK: Gender differences in high school students' dieting behavior and their correlates. Int J Mens Health 2002, I: 195-213.

44. Fugh-Berman A, Ernst E: Herb-drug interactions: Review and assessment of report reliability. J Clin Pharmacol 200I, 52:587-595

45. Report of the Commission on Dietary Supplement Labels. Washington, DC: Office of Disease Prevention and Health Promotion 1997.

\section{Pre-publication history}

The pre-publication history for this paper can be accessed here:

http://www.biomedcentral.com/1471-2458/5/47/prepub

\section{Publish with Bio Med Central and every scientist can read your work free of charge}

"BioMed Central will be the most significant development for disseminating the results of biomedical research in our lifetime. "

Sir Paul Nurse, Cancer Research UK

Your research papers will be:

- available free of charge to the entire biomedical community

- peer reviewed and published immediately upon acceptance

- cited in PubMed and archived on PubMed Central

- yours - you keep the copyright 